\title{
Vindingryke silwernitraat-impregneringstegniek vir varswater trigodina-taksonomie
}

\author{
Outeurs: \\ Gerhard P de Jager \\ L Basson \\ Affiliasies: \\ Departement Dierkunde en \\ Entomologie, Universiteit \\ van die Vrystaat \\ Posbus 339, Bloemfontein, \\ 9300, Suid-Afrika \\ Korresponderende outeur: \\ Gerhard de Jager \\ E-pos: dejagergp@ufs.ac.za \\ Hoe om hierdie artikel aan \\ te haal: \\ Gerhard P de Jager, \\ L Basson, \\ Vindingryke silwernitraat- \\ impregneringstegniek \\ vir varswater trigodina- \\ taksonomie, Suid- \\ Afrikaanse Tydskrif vir \\ Natuurwetenskap en \\ Tegnologie 39(1) (2020). \\ https://doi.org/10.36303/ \\ SATNT.2020.39.1.813 \\ Kopiereg: \\ (c) 2020. Authors. \\ Licensee: Die Suid- \\ Afrikaanse Akademie vir \\ Wetenskap en Kuns. \\ Hierdie werk is onder \\ die Creative Commons \\ Attribution License \\ gelisensieer.
}

\begin{abstract}
Novel silver nitrate impregnation techniques for freshwater trichodinid taxonomy: Trichodinids are unique protozoans that are symbionts of most aquatic animals. This group possesses a hard, internal structure that is impregnated with silver nitrate and then used for $\alpha$-taxonomy. This study reveals an innovative approach to this technique for successful staining in African environments and re-staining of archival material.
\end{abstract}

Trigodinas (Ciliophora: Peritricha) is eensellige, gesilieerde simbionte wat altyd met meersellige akwatiese gashere geassosieer word. Die spesifieke simbiotiese verhouding waarin trigodinas met hul gashere verkeer is nog 'n enigma, met sekere kenners wat hulle as patogene in akwakultuurboerderye bestempel en ander wat hulle as kommensialiste, en in uiterste gevalle selfs as mutualiste, sien. 'n Belangrike vraagstuk wat hierdie eukariote oopkrap, is hul evolusionêre plasing as gevolg van die feit dat trigodinas, anders as die res van die gesilieerdes, interne harde en artikulerende strukture - 'n tandring, besit. Die tandring bestaan uit individuele tandagtige strukture wat in mekaar skakel soos die werwels van 'n ruggraat, en dan 'n hegte, sterk ring vorm en dieselfde funksie as 'n werwelkolom vervul. Ironies is hierdie ringvormige "vertebraatkolom" ook die belangrikste uitkenbare morfologiese eienskap vir taksonomiese plasing op familie-, genus- en spesievlakke. Histories word die unieke vorm van elke tand uitgelig deur 'n histologiese kleuringstegniek, naamlik silwernitraat-impregnering. Ongelukkig is nog ' $n$ algemene eienskap van trigodinas dat hierdie impregnering selde konstante resultate lewer en dat die hidrologiese aspekte van die gasheerhabitat 'n baie groot rol in die kwaliteit van impregnering speel. Tradisioneel is hierdie tegniek op trigodinas vanaf gashere vanuit Europese varswaterstelsels ontwikkel en toegepas. Met die verskuiwing van navorsing op hierdie groep vanuit Europa na Suid-Afrika en Suid-Amerika na watermassas met geheel ander hidrologiese eienskappe, het hierdie tegniek as' $t$ ware in alchemie verander. Die behoefte aan hierdie studie het tydens ' $n$ navorsingsekspedisie na die Okavangodelta vir die taksonomiese beskrywing van 'n trigodina-spesie vanaf paddaviskieue na vore gekom. Tradisionele silwernitraat-impregnering vir trigodinas van hierdie gasheer was nog altyd uitdagend, maar in die Okavangodelta, waar die watermassa byna geen geleiding het nie, was dit rampspoedig (Fig. 1A). Verskeie eksperimente is in die veld, en later terug in die laboratorium gedoen, wat nie alleenlik in die suksesvolle impregnering vir hierdie moeilike gasheer asook uitdagende habitat gelei het nie, maar ook die suksesvolle her-impregnering van argiefmateriaal (ouer as 10 jaar) wat al verkleur het as gevolg van tyd (Fig. 1B). Resultate van die eksperimente kan as 'n behulpsame protokol dien vir enige morfologiese uitkenning vir trigodina-spesies vanaf amfibiese gashere, versamel gedurende veldtoestande uit varswatermassas vanaf Suider-Afrika (Fig. 1C), asook 'n protokol om verouderde smere in enige laboratorium te herwin vir verdere navorsing.
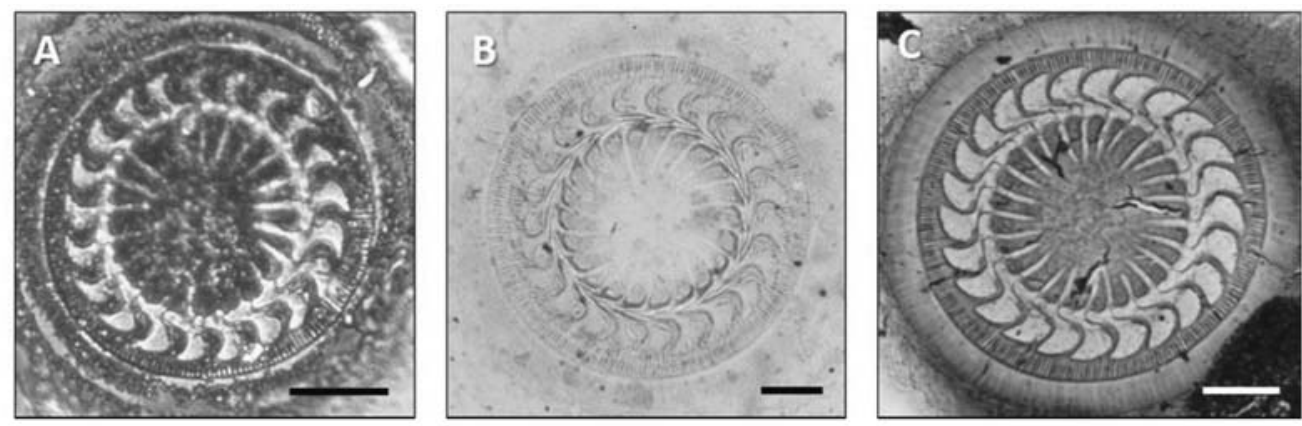

FIGUUR 1: Silwernitraat geïmpregneerde tandringe van Trichodina koloti de Jager, Basson en van Marwijk, 2019: A - tipiese impregnering van nuwe materiaal, $\mathrm{B}$ - verouderde smeer waarvan $\mathrm{AgNO}_{3}$ oor tyd verbleik het, en $\mathrm{C}$ - impregnering van nuwe materiaal met die huidige studie se protokol.

Nota: 'n Seleksie van referaatopsommings: Studentesimposium in die Natuurwetenskappe, 31 Oktober - 1 November 2019 Universiteit van die Vrystaat. Reëlingskomitee: Prof Rudi Pretorius (Departement Geografie, Universiteit van Suid-Afrika); Dr Hertzog Bisset (Suid-Afrikaanse Kernenergie-korporasie; Dr Ernie Langner (Departement Chemie, Universiteit van die Vrystaat) en Dr Wynand Nel (Departement Rekenaarwetenskap en Informatika, Universiteit van die Vrystaat). 